\title{
Long-term follow-up after combined fissurectomy and Botox injection for chronic anal fissures
}

\author{
Th. Scholz • F. H. Hetzer • D. Dindo • N. Demartines • \\ P. A. Clavien • D. Hahnloser
}

Accepted: 22 December 2006 / Published online: 30 January 2007

(C) Springer-Verlag 2007

\begin{abstract}
Background and aims Chronic anal fissures are difficult to treat. The aim of this retrospective study was to determine the outcome of combined fissurectomy and injection of botulinum toxin Type A (BT).

Materials and methods Between January 2001 and August 2004, 40 patients (21 women), median age 37 years (range 18 to 57), underwent fissurectomy and BT injection. Fissurectomy was performed followed by injection of $10 \mathrm{U}$ of BT into the internal anal sphincter on both sides of the fissure. All patients were clinically checked 6 weeks after the operation. At 1 year, patients were sent a detailed questionnaire regarding symptoms, recurrence and further treatment for evaluation of long-term results.

Results/findings At 6 weeks, 38 patients (95\%) were free of symptoms. No adverse effects were detected. The response rate of questionnaires was 93\%; the median follow-up was 1 year (range 0.9 to 1.6 ). In the long-term, a recurrence was found in four patients. These patients were treated successfully with repeated fissurectomy and BT injections and salvage procedures, respectively. Overall, the success rate of combined fissurectomy and BT injection was $79 \%$. Interpretation/conclusion Combined fissurectomy and Botox injection for chronic anal fissure is an excellent and safe procedure with low morbidity and a high healing rate.
\end{abstract}

Keywords Chronic anal fissure · Fissurectomy . Botulinum toxin type A $\cdot$ Long-term results

T. Scholz $\cdot$ F. H. Hetzer $\cdot$ D. Dindo $\cdot$ N. Demartines

P. A. Clavien $\cdot$ D. Hahnloser $(\bowtie)$

Department for Visceral and Transplantation Surgery,

University Hospital Zürich,

Rämistrasse 100,

8091 Zurich, Switzerland

e-mail: dieter.hahnloser@usz.ch

\section{Introduction}

The treatment of chronic anal fissures is still challenging. Whereas an acute fissure usually responds to conservative treatment in up to $90 \%$, chronic anal fissures are mainly refractory to non-surgical strategies with low healing rates of $30-40 \%$ [1]. Therefore, surgery is often mandatory in chronic fissures [2]. Since the first description by Notaras [3], lateral internal sphincterotomy (LIS) has become the treatment of choice for chronic anal fissures with a high healing rate of about 95\% [4]. However, LIS constantly showed a risk of incontinence to flatus in up to $45 \%$ [5-8] and for stool incontinence in up to $22 \%$ [9], respectively.

A high anal resting pressure leads to an impairment of anal blood supply and, thus, is considered to be a causative factor for the development of anal fissures. After 6-8 weeks, healing of the acute anal fissure is unlikely and should be considered chronic [10,11]. Besides a high resting anal pressure, the healing of chronic fissures is compromised by a sentinel skin tag and a hypertrophied anal papilla, which are very often inherent with chronic fissures [12].

Due to recent studies reporting faecal incontinence several years after LIS [7, 13-15], the medical reduction of the sphincter spasm by Botulinum toxin Type A (BT) is an alternative to surgery [16]. This exotoxin produces a constant reduction in maximum resting pressure for 2 3 months by binding to the presynaptic nerve terminal at the neuromuscular junction, thus, preventing the reuptake of acetylcholine [11, 17]. This chemical sphincterotomy is able to achieve healing rates up to $80 \%$ [18] and is, therefore, less favorable compared to LIS, while continence is not significantly affected $[16,19]$.

To increase healing rates of chronic anal fissures Gupta and Kalaskar [20] suggested to remove any sentinal skin tag and hypertrophied anal papilla during sphincterotomy, 
as these mechanical factors may compromise wound healing.

As high anal resting pressures as well as mechanical factors play an eminent role in the development of chronic anal fissures, reduction of the anal tone in combination with fissurectomy might be a promising novel approach. We hypothesize that fissure debridement is a keystone in the treatment of chronic anal fissures and combined it with BT injection. This new approach to chronic anal fissures has recently been documented with a complete healing rate of $93 \%$ by Lindsey et al. [19], but follow-up of these patients was limited to 16 weeks. Recurrences of surgically and medically treated chronic anal fissures can often develop beyond this time frame [13]. Therefore, we, here, present our long-term outcome of fissure debridement and BT injection together with patient's satisfaction.

\section{Materials and methods}

From January 2001 to August 2004, 40 consecutive patients with chronic anal fissures treated with fissurectomy combined with BT were enrolled in the study. Inclusion criteria were patients older than 16 years of age with persistent signs and symptoms of chronic anal fissures that lasted more than 6 weeks. Morphological signs of chronic anal fissures were defined as present fibrosis, induration of fissure edges and visible muscle fibres. Exclusion criteria were determined as acute fissure $(<6$ weeks), atypical fissure (multiple, irregular, off the midline), chronic fistulas in ano, coexsistence of inflammatory bowel disease, anal abscess, malignant disease, as well as post-obstetric and neutropenia-associated fissures.

After informed consent, fissurectomy was performed under general or regional anaesthesia. After examination of the fissure, the fibrotic edges were excised with a scalpel until a normal non-fibrotic anodermal tissue showing sufficient bleeding was reached. Then, a triangle was created at the distal edge of the fissure allowing wound drainage. If present, the sentinel skin tag was excised. The granulation tissue at the base of the fissure was curetted until there were clean muscle fibres of the internal anal sphincter. There was no use of diathermy, and careful attention was given not to damage the internal anal sphincter. Once fissurectomy was completed, $10 \mathrm{U}$ of BT (Allergan, Lachen, Switzerland) were injected on each side of the fissure into the internal anal sphincter (10 U BT were dissolved in $2 \mathrm{ml}$ of $0.9 \%$ natrium chloride solution). The injection site was adjacent to the location of the fissure. Patients were treated with stool regulation using Macrogolum 3350 (Transipeg ${ }^{\circledR}$; Mundipharma Medical, Basel, Switzerland) and topical lidocaine as anaesthetic agent for 6 weeks.
Six weeks after the operation, patients were re-evaluated in our outpatient clinic. Improvement of fissure healing and symptoms relief at 6 weeks were graded in four different stages as described by Lindsey et al. [10]:

I. Fissure healed/symptoms resolved/no surgery required II. Fissure unhealed/symptoms resolved/no surgery required

III. Fissure unhealed/symptoms satisfactorily improved/no surgery required

IV. Fissure unhealed/symptoms not satisfactorily improved/surgery required

Incontinence was documented according to the Wexner score [9]. Fissure healing was defined as completely resolved symptoms according to stages I and II as described above.

One year after surgery, all patients were sent a detailed questionnaire regarding symptoms and patients' satisfaction. The two classical symptoms of chronic anal fissures (postdefecatory pain and bleeding) were compared with baseline parameters preoperatively. Overall satisfaction of patients concerning the treatment was evaluated using the visual analogue scale. Related to the questionnaire, healing was again defined as completely resolved symptoms.

Differences of symptoms within the study group were statistically analysed for paired data and a dichotomous endpoint using the Mc Nemar test. A $p<0.05$ was considered significant. Data are presented as median (range).

\section{Results}

Patient demographics

Forty patients ( 21 women) with a median age of 37 years (range 18-57 years) were treated with fissurectomy combined with BT injection. Thirty-four (85\%) fissures were posterior, and six were located at the anterior portion. A sentinel skin tag was present in $26(65 \%)$ patients. During the study period, 152 patients were conservatively treated for an acute anal fissure in our hospital. Thirty patients $(20 \%)$ were not responding to this therapy after 3 months (range 2 to 6 months) and were enrolled into the study. Twelve patients were primarily seen for chronic anal fissure with a median duration of symptoms of 16 months (range 15 to 19 months).

Surgical complications and morbidity

Surgical complications were graded according to a validated treatment-orientated score [21]. Five patients presented with a grade I complication (any deviation from the normal 
postoperative course without the need for pharmacological treatment or surgical, endoscopic and radiological interventions). One of these patients complained about mild incontinence 6 weeks after surgery (Wexner score 5). Incontinence improved by dietary measures and completely disappeared as evaluated during long-term follow-up. Three of these patients presented with ongoing anal bleeding that spontaneously resolved on the first postoperative day. The fifth patient developed a small abscess that drained and healed spontaneously. No complications requiring surgical or pharmacological intervention (grades II to III) were observed.

\section{Short-term outcome}

Six weeks after the operation, all 40 patients were reevaluated and interviewed in our outpatient clinic. Ten patients $(25 \%)$ had a completely healed fissure and resolved symptoms (stage I). In 26 patients (65\%), the fissure was still present, but there were no complaints of any symptoms at all (stage II). Four patients (10\%) presented with persistent symptoms and unhealed fissures (stage IV), of which, two were successfully treated by a second fissurectomy and BT injection. Therefore, the primary short-term success concerning fissure healing was 90\% (36/40).

\section{Long-term outcome}

After a median of 1 year (range 0.9 to 1.6 years), all patients were sent a detailed questionnaire for evaluation of the longterm follow up. The response rate was 93\% (37/40). Figure 1 shows the reduction of typical fissure symptoms compared

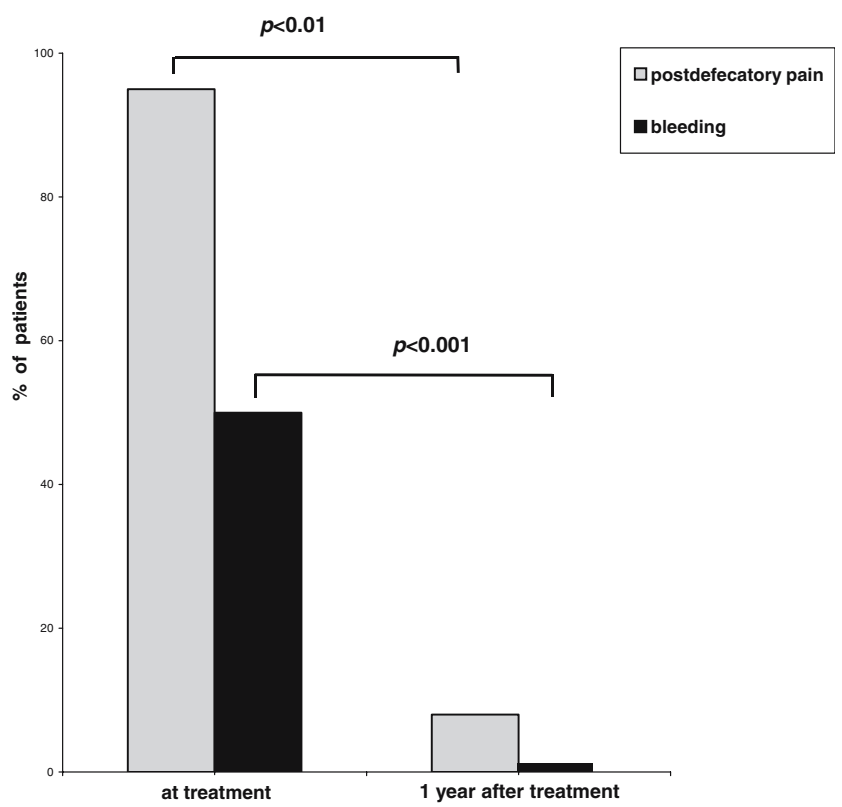

Fig. 1 Long-term follow-up of symptoms as determined by questionnaires to the preoperative baseline values: Postdefecatory pain significantly improved by $92 \%(P<0.01)$ and bleeding by $100 \%(P<0.001)$, respectively.

Four patients who presented with short-term failure after 6 weeks were all without complaints after 1 year. In two patients, repeated fissurectomy and injection of BT was successfully performed. The other two patients were treated conservatively by dietary measures. Another four patients who showed healing in the 6-week follow-up developed a recurrence of the fissure requiring further treatment (stage IV). Overall, total healing rate was $79 \%$ according to the Kaplan-Meier analysis after fissurectomy and BT injection.

Patients' satisfaction

With the questionnaire, we evaluated the overall satisfaction of our therapy using a visual analogue scale $(0=$ not at all-10 = very satisfied) resulting in a median of 9 (range 7 to 10 ) among all 37 patients.

\section{Discussion}

The combination of fissurectomy and BT achieved an excellent healing rate of $79 \%$ after 1 year. The procedure was safe with low morbidity, and only one reported mild disturbance in continence in the first weeks postoperatively.

Although LIS demonstrated excellent results regarding fissure healing and continence due to a significant decline in resting anal pressure [13], numerous reports revealed a significant risk for developing disturbances in anal continence with a reported incontinence to flatus from 6 to $35 \%$ and minor faecal soiling from 8 to $22 \%$ in the long-term [2, $5,14,22]$. Today, it is known that faecal incontinence may occur many years after sphincter damage such as from complicated delivery or anal surgery [23]. For that reason, incontinence after LIS has probably been underestimated [7].

In recent years, there has been a shift towards medical therapy to overcome these surgical side effects. A deeper understanding of the physiology of the anal sphincter allowed medical approaches to influence the sphincter tone [24]. Since the introduction of BT for chronic anal fissure in 1994 [25], many studies have been conducted to evaluate its role and effectiveness. Short-term results of the first studies have been very promising, with healing rates of 60$70 \%$ [26, 27]. Thereafter, numerous reports described healing rates with single injection of BT between $40-90 \%$ $[1,10,16]$. However, with meta-analysis, healing rates are found to be always lower than $80 \%$ and, therefore, BT is still inferior to surgical procedures [11, 18, 28-30]. This is underlined by De Nardi et al. [1] showing recently that BT failed in one third of patients after 3 months. In the longterm, healing rate was only $40 \%$ after 46 months. 
We believe that BT is effective in the reduction of anal resting pressure, but many patients with chronic anal fissure show clear signs of chronicity (indurated fissure edges, scar tissue, hypertrophied anal papilla and sentinel skin tag) and, therefore, the concept of BT alone is not able to overcome these pathophysiological features needed to achieve appropriate tissue healing. Fissurectomies with removal of the fibrotic edges of the fissure and resection of anal papilla and the skin tag, respectively, have been successfully applied as alternative for LIS in the treatment of chronic anal fissures in pediatric studies [31]. The concept of fissurectomy in combination with reversible chemical sphincterotomy as used in the present study was first introduced by Engel et al. [32]. After a 29-month followup, all 17 patients showed a healed anal fissure after fissurectomy followed by nitroglycerin (GTN) application. Lindsey et al. [19] reported complete healing rates of $93 \%$ by fissurectomy and injection of BT after 4 months. These and our data demonstrate that a combined strategy consisting of fissurectomy and chemical sphincterotomy is a promising approach with low morbidity.

Nitrates such as GTN are effective and inexpensive drugs for reduction of anal resting pressure. However, side effects may compromise patient's compliance, as headache has been reported to occur in up to $72 \%$ [1,33-35]. Several manometric studies have demonstrated $\mathrm{BT}$ to be as effective as nitrates with less side effects $[25,26,36]$; although incontinence of flatus and stool incontinence has been reported in up to 10 and $5 \%$, respectively, dependent on dosage [18]. However, in our study using $10 \mathrm{U}$ of BT, mild stool incontinence was only observed in one patient $(2.5 \%)$. The main disadvantage of BT is its expensiveness (100 U Botox ${ }^{\circledR}$ costs 350 euro). Nevertheless, a single drug injection and low morbidity make BT more favourable to nitrates. Overall, treatment with GTN, nifedipin, diltiazem and lidocaine has also been shown to be ineffective [30].

BT causes paralysis of skeletal muscles blocking the presynaptic release of acetylcholine. Therefore, BT was first injected into the external sphincter [25]. Recent studies have demonstrated that BT may also be effective in nonstriated muscle fibres. Jones et al. [36] showed that injection of BT into the internal anal sphincter reduces the myogenic tone and contractile response to sympathetic stimulation. In this study, BT was injected into the internal anal sphincter. Overall, clear information about dosage, precise injection site and number of injections is still incomplete.

In addition to BT injection, a fissurectomy, as described by Gupta et al. [12], was performed in all patients in our study. The fibrotic edges of the fissure were excised as well as any sentinel skin tag and hypertrophied anal papilla. Great emphasis was led on the formation of a drainage triangle at the distal end of the fissure to allow constant wound drainage.
In conclusion, fissurectomy and BT injection treats both main causes of chronicity of anal fissures: the presence of bradytrophic scar tissue and the high resting anal pressure. This combined treatment strategy is very promising for the treatment of chronic anal fissures with a high success rate and a low morbidity. Further randomized trials comparing fissurectomy alone versus fissurectomy combined with BT have to reveal whether fissurectomy alone can be as effective as combined therapies.

\section{References}

1. De Nardi P, Ortolano E, Radaelli G, Staudacher C (2006) Comparison of glycerine trinitrate and botulinum toxin-a for the treatment of chronic anal fissure: long-term results. Dis Colon Rectum 4:427-432

2. Oh C, Divino CM, Steinhagen RM (1995) Anal fissure. 20-year experience. Dis Colon Rectum 4:378-382

3. Notaras MJ (1969) Lateral subcutaneous sphincterotomy for anal fissure-a new technique. Proc R Soc Med 7:713

4. Argov S, Levandovsky O (2000) Open lateral sphincterotomy is still the best treatment for chronic anal fissure. Am J Surg 3:201202

5. Nyam DC, Pemberton JH (1999) Long-term results of lateral internal sphincterotomy for chronic anal fissure with particular reference to incidence of fecal incontinence. Dis Colon Rectum 10:1306-1310

6. Ortiz H, Marzo J, Armendariz P, De Miguel M (2005) Quality of life assessment in patients with chronic anal fissure after lateral internal sphincterotomy. Br J Surg 7:881-885

7. Casillas S, Hull TL, Zutshi M, Trzcinski R, Bast JF, Xu M (2005) Incontinence after a lateral internal sphincterotomy: are we underestimating it? Dis Colon Rectum 6:1193-1199

8. Lindsey I, Jones OM, Cunningham C, Mortensen NJ (2004) Chronic anal fissure. Br J Surg 3:270-279

9. Jorge JM, Wexner SD (1993) Etiology and management of fecal incontinence. Dis Colon Rectum 1:77-97

10. Lindsey I, Jones OM, Cunningham C, George BD, Mortensen NJ (2003) Botulinum toxin as second-line therapy for chronic anal fissure failing 0.2 percent glyceryl trinitrate. Dis Colon Rectum 3:361-366

11. Brisinda G, Maria G, Bentivoglio AR, Cassetta E, Gui D, Albanese A (1999) A comparison of injections of botulinum toxin and topical nitroglycerin ointment for the treatment of chronic anal fissure. N Engl J Med 2:65-69

12. Gupta PJ (2004) Hypertrophied anal papillae and fibrous anal polyps, should they be removed during anal fissure surgery? World J Gastroenterol 16:2412-2414

13. Ram E, Alper D, Stein GY, Bramnik Z, Dreznik Z (2005) Internal anal sphincter function following lateral internal sphincterotomy for anal fissure: a long-term manometric study. Ann Surg 2:208211

14. Rotholtz NA, Bun M, Mauri MV, Bosio R, Peczan CE, Mezzadri NA (2005) Long-term assessment of fecal incontinence after lateral internal sphincterotomy. Tech Coloproctology 2:115-118

15. Floyd ND, Kondylis L, Kondylis PD, Reilly JC (2006) Chronic anal fissure: 1994 and a decade later — are we doing better? Am J Surg 3:344-348

16. Arroyo A, Perez F, Serrano P, Candela F, Calpena R (2005) Long-term results of botulinum toxin for the treatment of chronic anal fissure: prospective clinical and manometric study. Int J Colorectal Dis 3:267-271 
17. Brisinda G, Cadeddu F, Brandara F, Brisinda D, Maria G (2004) Treating chronic anal fissure with botulinum neurotoxin. Nat Clin Pract Gastroenterol Hepatol 2:82-89

18. Orsay C, Rakinic J, Perry WB, Hyman N, Buie D, Cataldo P, Newstead G, Dunn G, Rafferty J, Ellis CN, Shellito P, Gregorcyk S, Ternent C, Kilkenny J 3rd, Tjandra J, Ko C, Whiteford M, Nelson R (2004) Practice parameters for the management of anal fissures (revised). Dis Colon Rectum 12:2003-2007

19. Lindsey I, Cunningham C, Jones OM, Francis C, Mortensen NJ (2004) Fissurectomy-botulinum toxin: a novel sphincter-sparing procedure for medically resistant chronic anal fissure. Dis Colon Rectum 11:1947-1952

20. Gupta PJ, Kalaskar S (2003) Removal of hypertrophied anal papillae and fibrous anal polyps increases patient satisfaction after anal fissure surgery. Tech Coloproctology 3:155-158

21. Dindo D, Demartines N, Clavien PA (2004) Classification of surgical complications: a new proposal with evaluation in a cohort of 6336 patients and results of a survey. Ann Surg 2:205-213

22. Khubchandani IT, Reed JF (1989) Sequelae of internal sphincterotomy for chronic fissure in ano. Br J Surg 5:431-434

23. Lunniss PJ, Gladman MA, Hetzer FH, Williams NS, Scott SM (2004) Risk factors in acquired faecal incontinence. J R Soc Med 3:111-116

24. Jones OM, Brading AF, Mortensen NJ (2002) The physiology, pharmacology and therapeutic manipulation of the internal anal sphincter. Can J Gastroenterol 4:249-257

25. Jost WH, Schimrigk K (1994) Therapy of anal fissure using botulin toxin. Dis Colon Rectum 12:1340

26. Gui D, Cassetta E, Anastasio G, Bentivoglio AR, Maria G, Albanese A (1994) Botulinum toxin for chronic anal fissure. Lancet 8930:1127-1128
27. Maria G, Cassetta E, Gui D, Brisinda G, Bentivoglio AR, Albanese A (1998) A comparison of botulinum toxin and saline for the treatment of chronic anal fissure. N Engl J Med 4:217220

28. Jost WH (1997) One hundred cases of anal fissure treated with botulin toxin: early and long-term results. Dis Colon Rectum 9:1029-1032

29. Maria G, Brisinda G, Bentivoglio AR, Cassetta E, Gui D, Albanese A (1998) Botulinum toxin injections in the internal anal sphincter for the treatment of chronic anal fissure: long-term results after two different dosage regimens. Ann Surg 5:664-669

30. Nelson R (2004) A systematic review of medical therapy for anal fissure. Dis Colon Rectum 4:422-431

31. Lambe GF, Driver CP, Morton S, Turnock RR (2000) Fissurectomy as a treatment for anal fissures in children. Ann R Coll Surg Engl 4:254-257

32. Engel AF, Eijsbouts QA, Balk AG (2002) Fissurectomy and isosorbide dinitrate for chronic fissure in ano not responding to conservative treatment. Br J Surg 1:79-83

33. Kocher HM, Steward M, Leather AJ, Cullen PT (2002) Randomized clinical trial assessing the side-effects of glyceryl trinitrate and diltiazem hydrochloride in the treatment of chronic anal fissure. Br J Surg 4:413-417

34. Mustafa NA, Cengiz S, Turkyilmaz S, Yucel Y (2006) Comparison of topical glyceryl trinitrate ointment and oral nifedipine in the treatment of chronic anal fissure. Acta Chir Belg 1:55-58

35. Nelson R (2003) Non surgical therapy for anal fissure. Cochrane Database Syst Rev 4:CD003431

36. Jones OM, Moore JA, Brading AF, Mortensen NJ (2002) The site and mechanism of action of botulinum toxin on the porcine anal sphincter. Colorectal Dis 1:71 